\title{
A EDUCAÇÃO AMBIENTAL NO ÂMBITO ESCOLAR: UM ESTUDO EM UMA ESCOLA MUNICIPAL DE SÍTIO NOVO (RN)
}

Aylana Laíssa Medeiros Borges ${ }^{1}$ João Correia Saraiva Junior ${ }^{2}$

Resumo: Em função das questões ambientais da contemporaneidade, é importante que a educação ambiental faça parte dos currículos escolares, uma vez que o papel principal da escola não é apenas ensinar a ler e escrever, mas também formar cidadãos conscientes de seus direitos e deveres sociais. A presente pesquisa com o objetivo de verificar como os docentes de uma escola municipal aborda a temática ambiental no âmbito escolar, tem abordagem quali-quantitativa. Os resultados apontaram que o município estudado possui recursos naturais merecedores de cuidado, e quanto à discussão da temática ambiental em sala de aula, constatou-se que os docentes ainda não trabalham de forma transdisciplinar, pois as ações realizadas com intuito de promover a educação ambiental são meramente pontuais.

Palavras-chave: Recursos Naturais; Educação Ambiental; Ambiente Escolar.

\footnotetext{
${ }^{1}$ Instituto Federal de Educação, Ciência e Tecnologia do Rio Grande do Norte-IFRN. E-mail: aylanaborges@outlook.com

2Instituto Federal de Educação, Ciência e Tecnologia do Rio Grande do Norte-IFRN. E-mail: joao.correia@ifrn.edu.br
}

revista brasileira educação ambiental 


\section{Introdução}

A visitação a ambientes naturais tornou-se frequente e vem sendo bastante estimulada, pois estar em contato com o meio ambiente tornou-se sinônimo de bem-estar, saúde, dentre outros, diversão, além de ser considerado uma forma de distanciar-se do cotidiano estressante, corrido e repleto de preocupações.

Nessa perspectiva, entende-se que a interação homem-natureza foi transformada em um produto capaz de ser comercializado e consumido, e tem atraído um fluxo cada vez maior de pessoas. No entanto, tem-se que os espaços naturais devem ser utilizados de maneira orientada e equilibrada, considerando que o desgaste causado pela má conduta dos usuários, sejam eles visitantes e/ou os próprios residentes da localidade, podem prejudicar estes ambientes de forma até mesmo irreversível.

Frente a esta conjuntura, acredita-se que uma comunidade sensível e consciente dos recursos que possui é algo importante para a conservação dos elementos naturais do lugar, tornando-se esse um passo significativo para que se tenha e/ou faça o uso do ambiente natural de maneira moderada e harmoniosa.

Assim sendo, Santos e Santos (2011, p. 1) explicam que "a educação ambiental é uma forma de consolidação para uma consciência ecológica e uma prática efetiva do turismo sustentável em áreas de proteção ambiental". Vale salientar que a educação ambiental é capaz de construir uma consciência ecológica não apenas voltada para a prática de atividades em áreas de proteção, mas também para a visitação aos ambientes naturais de uma maneira geral.

Partindo dessa concepção, compreende-se a necessidade em estimular ações voltadas para a prática da educação ambiental trabalhando a sensibilidade dos cidadãos quanto a importância do meio ambiente, de maneira que tais ações despertem e chamem a atenção do poder público, comunidade escolar e outros, para posturas mais eficazes para a gestão ambiental de uma localidade.

Entende-se também que os cuidados com o meio ambiente não são de responsabilidade apenas do poder público, pois soma-se a esse as sociedades civis organizadas, as instituições de ensino, e a própria comunidade local. Portanto, é preciso estimular comportamentos e/ou hábitos mais sustentáveis no tocante ao uso dos recursos naturais, e um passo inicial seria sensibilizar crianças, jovens e adultos.

Explica-se que tal sensibilização pode ser realizada por meio da educação ambiental nas escolas, ferramenta de grande contribuição, devendo ser desenvolvida de forma continuada. Assim sendo, tem-se como problemática, para elaboração deste artigo, a seguinte questão: De que maneira os docentes de uma escola municipal de Sítio Novo (RN) vêm trabalhando os aspectos ambientais da localidade para fins de sensibilização 
dos estudantes quanto a importância da reponsabilidade com os recursos naturais existentes?

Este artigo tem como objetivo geral verificar como os docentes de uma escola municipal de Sítio Novo (RN) abordam as questões ambientais no âmbito escolar, especialmente referindo-se às reflexões sobre o uso comedido dos recursos naturais da localidade. Desse modo, destacam-se como objetivos específicos: identificar os recursos e/ou ambientes naturais do município de Sítio Novo (RN); caracterizar as formas de uso desses espaços; e verificar como os docentes da rede municipal de ensino abordam as questões ambientais em sala de aula.

A referida proposta, para este recorte espacial, justifica-se pelo município de Sítio Novo destacar-se pelos seus recursos naturais e por ter seu ambiente natural explorado algumas vezes de maneira desordenada, seja pelos munícipes ou visitantes locais.

Desse modo, acredita-se que estimular uma educação ambiental voltada para o entendimento da importância dos recursos naturais do lugar, e de que forma esse pode ser conservado e/ou preservado torna-se uma ação de grande significância. E atrelado a esse fato, tem-se que a comunidade escolar se mostra como um parceiro importante para iniciar este processo, uma vez que estar-se-á em um ambiente de formação de cidadãos que devem estar comprometidos com os diferentes aspectos (culturais, ecológicos, econômicos, sociais, entre outros) que compõem a sociedade.

Com relação a metodologia da pesquisa, este estudo se caracteriza como uma pesquisa do tipo bibliográfica e exploratória, de caráter qualitativoquantitativo, com a realização de visita de campo e a aplicação de questionário. Selecionou-se para tanto como campo de estudo uma escola municipal de Sítio Novo, sendo esta: a Escola Municipal Presidente Garrastazu Médici, localizada na sede do município.

A proposta deste estudo foi realizada com o corpo docente, que ministra aulas nas turmas de $5^{\circ}$ a $9^{\circ}$ ano da referida escola a fim de identificar como esses atores vêm trabalhando as questões ambientais no âmbito escolar para fins de sensibilização do alunado quanto a importância dos recursos naturais para a sobrevivência do homem, e enquanto elementos que devem ser valorizados. Essa etapa constituiu-se pela elaboração e aplicação de um questionário de pesquisa.

Com o intuito de caracterizar a área de estudo, elucida-se que o município de Sítio Novo, no Rio Grande do Norte, encontra-se aproximadamente a $99 \mathrm{Km}$ de Natal, capital do Estado (FEMURN, 2015) apresenta uma paisagem natural rica e que permite a prática de atividades de aventura, como rapel, tirolesa, trilhas, escalada, dentre outros (TAVEIRA, 2015). Nesse contexto, a atenção com o meio ambiente se torna ainda mais necessária, uma vez que este cenário atrai pessoas para visitação e usufruto 
do espaço natural para fins de lazer e/ou para a prática das referidas atividades.

As vias de acesso ao município de Sítio Novo são as seguintes: BR 226, a partir de Natal, rodovia pavimentada; RN - 093, rodovia Estadual que liga o município de Tangará a Sítio Novo; e a RN - 203, acesso a partir de Lagoa de Velhos, estrada de barro (FEMURN, 2015) (Figura 1, próxima página).

Logo, no decorrer desse artigo, tem-se o referencial teórico, elaborado para consubstanciar os resultados obtidos a partir do estudo; os resultados da pesquisa; e as considerações finais, destacando os aspectos encontrados com a investigação, e as sugestões para novos estudos.

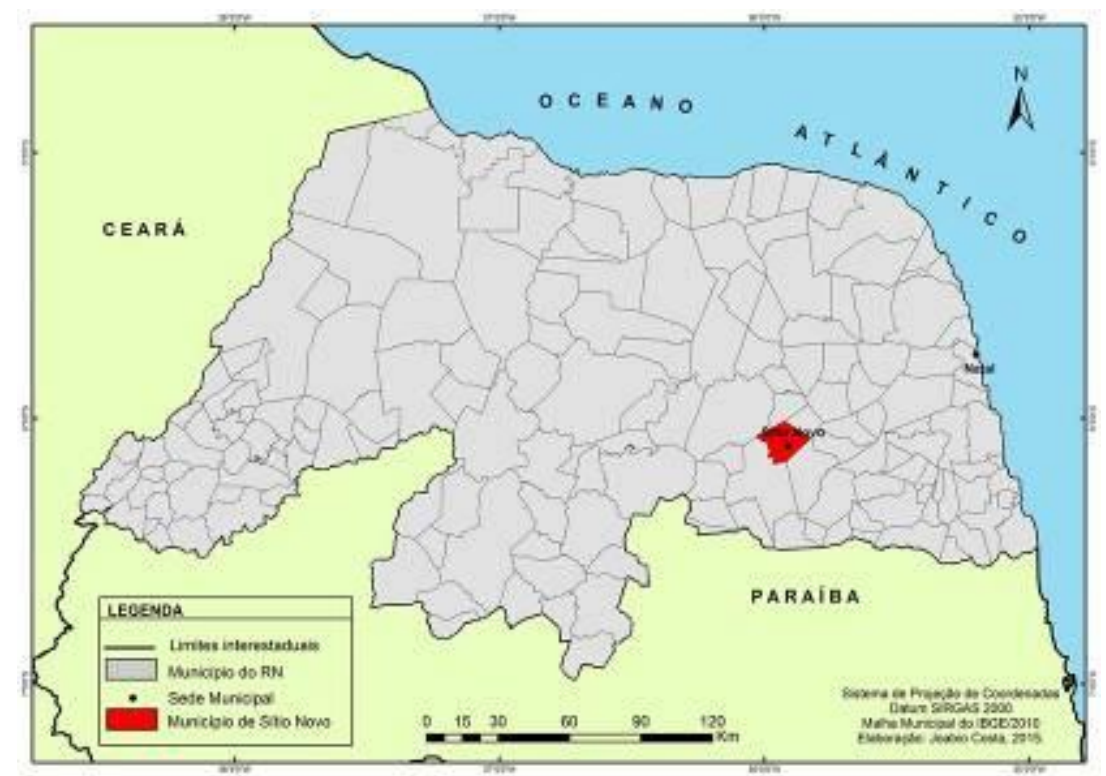

Figura 1: Localização de Sítio Novo/RN

Fonte: TAVEIRA, Marcelo da Silva (coordenador). Inventário Turístico de Sítio Novo/RN. Currais Novos: UFRN (2015).

\section{Meio ambiente: aspectos históricos da construção de um conceito}

Antes de tratar acerca da Educação Ambiental no âmbito escolar, é interessante discutir um pouco sobre o processo histórico que envolve o tema meio ambiente.

Assim sendo, tem-se que a preocupação com o meio ambiente teve início na década de 70 , em virtude do modelo industrial vigente na época. Tal modelo encadeou uma série de problemas ambientais que levaram a realização de eventos como a primeira Conferência das Nações Unidas para o Meio Ambiente Humano, realizada em Estocolmo, na Suécia, no ano de 1972 (DA CONFERÊNCIA, 2015).

A Conferência de Estocolmo, como ficou conhecida, teve o intuito de discutir temas referentes a preservação e melhoramento do ambiente humano, 
"compreendendo este ambiente humano como os ambientes do planeta Terra onde existam e convivam seres humanos" (PORTAL EDUCAÇÃO, 2012, p. 1).

De maneira geral, o referido evento procurou encontrar soluções para os problemas ambientais, de modo a discutir a temática de forma mais séria e organizada, haja vista os problemas como a poluição das águas, o desmatamento, a poluição do solo, além de outros.

$\mathrm{Na}$ década de 80 , as preocupações com o meio ambiente aumentaram e por essa razão foi criada, em 1983, a Comissão Mundial sobre Meio Ambiente e Desenvolvimento. Essa comissão teve como intuito discutir o desenvolvimento econômico considerando os recursos naturais disponíveis, de maneira a propor novas formas de cooperação internacional quanto a orientar as políticas e ações no sentido das mudanças necessárias (TAGORE, 2009). O autor ainda esclarece que em 1987 a comissão recomendou a criação de uma nova carta - o Relatório Brundtland, esse que teve como foco tratar sobre como utilizar os recursos naturais de forma consciente.

Em 1990, as discussões sobre meio ambiente tornaram-se mais frequentes, tendo sido elaborada a Agenda 21, documento que descrevia como os países poderiam contribuir com as questões ambientais, considerando o desenvolvimento de cada um. De acordo com o Ministério do Meio Ambiente (2015) a Agenda 21 apresenta-se como um instrumento de planejamento para a construção de sociedades sustentáveis, que concilia métodos de proteção ambiental, justiça social e eficiência econômica.

Conforme Pelicioni (2004, p. 477) a Agenda 21 é considerada o principal plano global para contornar e superar problemas ecológicos e econômicos, e por essa razão "não pode ser considerado um documento estático, acabado, pois a própria realidade é dinâmica e mutável, assim como também as necessidades e interesses da população".

Enveredando nos acontecimentos do final do século $X X$, quando passou-se a discutir sobre o desenvolvimento sustentável das localidades, destaca-se esse como um momento de grande significância para todos, uma vez que tratava-se sobre a busca pela sustentabilidade. Assim, no ano de 1999, criou-se a Lei no 9.795 que trata da Política Nacional de Educação Ambiental, momento em que decidiu-se educar pessoas acerca da relevância do meio ambiente para a sobrevivência de todos.

Conforme a Lei oㅜ 9.795 de 27 de abril de 1999, em seu art. 2º , a educação ambiental é um componente essencial e permanente da educação nacional, devendo estar presente, de forma articulada, em todos os níveis e modalidades do processo educativo, em caráter formal e não-formal.

Nessa perspectiva, acredita-se que estimular as pessoas a buscar informações consistentes e modificar comportamentos em relação as formas de uso dos recursos ambientais é de grande valia, especialmente quando estar-se-á fazendo uso desse de forma inadequada. 


\section{Educação Ambiental no contexto escolar}

$\mathrm{Na}$ contemporaneidade os recursos naturais passaram a ser utilizados de forma desordenada, especialmente em virtude da busca pelo desenvolvimento econômico desmedido.

Nesse sentido, conforme Nascimento e Araújo (2011) a educação ambiental tem um importante papel de intermediar a reintegração homem/natureza, mediante o descuido em relação a sua preservação. Os autores ainda explicam que essa contribuição pode ser oferecida por meio de atitudes, valores, conhecimentos e a inserção dos educadores e educandos nesse processo de transformação, desse cenário de gradativa destruição.

Assim, a "educação ambiental se faz necessária para que as pessoas sejam esclarecidas e possam, de maneira consciente e cidadã, opinar sobre projetos que certamente influenciarão suas vidas e suas comunidades por muito tempo" (LINDNER, 2012, p. 15). De acordo com o autor, o componente educacional precisa preocupar-se em informar e formar pessoas com uma nova visão de sociedade.

E nessa perspectiva, "a escola desempenha um papel fundamental na garantia desse despertar da consciência para os valores ambientais, na medida em que tem o poder de, ao educar os alunos, formar cidadãos" (NASCIMENTO; ARAUJO, 2011, p.29).

Entende-se que essa nova visão estaria relacionada a tomada de decisão em função de um objetivo comum, envolvendo diferentes atores e de forma a beneficiar o todo. O sistema educacional deve buscar ações e estratégicas para que as pessoas entendam as relações atuais de produção e consumo e suas futuras implicações que causariam problemas na manutenção da vida em nosso planeta (LINDNER, 2012).

Frente ao contexto, segundo Kindel (2012, p. 15) educar ambientalmente significa, "a apropriação de conceitos e processos que tratem acerca do ambiente, a aquisição de visões de mundo que possibilitem o respeito e o entendimento de que a vida se dá pelas complexas relações entre os elementos naturais e socioculturais". O autor acrescenta que a escola se configura em um espaço que reúne pessoas em torno do conhecimento e possibilidades de mudar para melhor o indivíduo, sua vida, seu entorno e suas relações com o mundo natural e social.

Um fato interessante é que "a educação ambiental pode ter, como ponto de partida, o trabalho com a realidade local, sem perder de vista que os alunos precisam compreender que a tessitura da vida no planeta é complexa" (KINDEL, 2012, p. 26).

Acredita-se que o aprendizado estimulado levando em consideração a realidade local pode favorecer uma visão mais prática dos problemas, e a busca por soluções mais especificas, de maneira que permita as pessoas enxergarem sua realidade. 
Frente a conjuntura, seria interessante que as escolas trabalhassem a transversalidade, permitindo que uma questão ambiental local, como tratamento de esgotos ou problemática de resíduos sólidos, pudesse ser estudada, discutida e debatida por diferentes áreas com o intuito de serem encontradas soluções possíveis de serem compartilhadas por toda comunidade (KINDEL, 2012). O autor esclarece que cada disciplina pode contribuir para a elaboração de um mapa local, permitindo que os alunos passem a conhecer por meio da disciplina de história, por exemplo, os fatos históricos locais; dentre outros, na disciplina de ciências naturais, passar a compreender os elementos naturais existentes na localidade e de que forma utilizá-los de maneira consciente.

De acordo com os Parâmetros Curriculares Nacionais - PCNS (BRASIL, 2000, p. 193) "trabalhar de forma transversal significa buscar a transformação dos conceitos, a explicitação de valores e a inclusão de procedimentos, sempre vinculados à realidade cotidiana da sociedade, de modo que obtenha cidadãos mais participantes". Explica-se ainda que para este caso, os professores, dentro da especificidade de sua área, devem adequar o tratamento dos conteúdos para contemplar o tema meio ambiente e/ou outro tema em suas aulas.

Nessa perspectiva, Pelicioni (2004, p. 473) esclarece que "a educação ambiental é fundamental na obtenção dos objetivos e metas estabelecidos para uma adequada gestão ambiental, em qualquer localidade". Ainda segundo o autor a eficiência dessa gestão será determinada pelo grau de educação da população local, e que, portanto dentre os objetivos da educação ambiental está preparar os indivíduos para uma participação popular significativa.

Sendo assim, considerando essa preparação dos indivíduos e que no Brasil buscou-se avançar ao colocar a EA como parte integrante da educação formal, por meio da política nacional de educação, torna-se interessante identificar como essa prática vem sendo desenvolvida em municípios interioranos, de forma contínua e permanente nos diferentes níveis e modalidades de ensino formal. Vale realçar que o Estado do RN se destaca no tocante à reflexão sobre 0 uso e preservação dos recursos naturais, especialmente em razão de estar localizado em uma costa litorânea, mas também por dispor de regiões com relevo mais elevado no interior, que permite desfrutar de belezas como as serras, rochas, lajedos e outros (O ESTADO, 2015).

Diante desse fato, educar a comunidade escolar para um comportamento ambientalmente saudável contribuirá para uma melhor qualidade dos recursos naturais existentes, além de fazer com que o aprendizado em sala de aula chegue até o ambiente residencial de cada um. Assim, foi na perspectiva de entender como uma escola no interior do Estado do $\mathrm{RN}$, que é marcado por belezas naturais que despontam com serras, rochas, cavernas, e outros, contribuem para uma formação ambiental do alunado de forma a incentivar a valorização desses recursos. 


\section{Sítio Novo e seus recursos naturais}

No que compete aos recursos naturais, identificou-se que Sítio Novo dispõe de elementos capazes de encantar a visitantes, porém a comunidade local ainda não despertou para a riqueza existente na localidade, uma vez que não se constatou ações comunitárias, em se tratando da comunidade escolar, voltadas para a conservação do meio ambiente. Explica-se que pesquisas no site da prefeitura foram realizadas a fim de identificar tais ações.

Assim, elenca-se a seguir os recursos naturais existentes no município e que o caracterizam como destino capaz de atrair pessoas e/ou grupos para prática de atividades de aventura e lou ecoturismo.

No ano de 2015 foi elaborado o inventário turístico de Sítio Novo, tendo o referido trabalho sido produzido pelo docente, Marcelo da Silva Taveira, e pelo estudante do Curso de Turismo da UFRN, Diego Filgueira. Nesse, foram levantadas informações quanto a: infraestrutura de apoio ao turista; serviços e equipamentos turísticos; e atrativos turísticos locais.

Desse modo, o referido inventário é relevante para esse estudo, uma vez que permite identificar dentre os atrativos turísticos mencionados, os que se destacam enquanto atrativos naturais.

Apresentam-se, portanto, para fins desta pesquisa, as informações que se referem ao potencial natural existente no município, a saber: a Pedra de São Pedro; Pedra do Letreiro e Olho d'água; Açude Barra da Tapuia; Mirante do Cruzeiro de São Francisco; Tanque da Vaca; Serra da Pitombeira; Serra da Inês; e Sítio Catolé (COSTA, 1992; TAVEIRA, 2015). Nestes locais tem-se potencial para a prática de atividades como ecoturismo, esportes de aventura, e além de outros, a realização de trilhas ecológicas (Quadro 1, próxima página):

Taveira (2015) no inventário descreve ainda as possíveis atividades que podem ser desenvolvidas nos lugares anteriormente citados, e menciona 0 que pode ser encontrado nesses ambientes. Assim, explica-se que no território da (o):

1. Pedra de São Pedro: encontra-se o olho d'água, inscrições rupestres, cavernas e mirantes.

2. Tanque da Vaca: inscrições rupestres, cavernas, mirantes, reservatório natural d'água.

3. Serra da Pitombeira: caverna da caveira, cachoeira da caveira, inscrições rupestres, além de mirantes e reservatório d'água natural.

4. Serra da Inês: cavernas, mirantes, e minério cristal de rocha.

5. Sítio Catolé: inscrições rupestres, cavernas, casa de pedra e mirantes. 
Quadro 1: Localização de Sítio Novo (RN) e imagens dos recursos naturais/culturais.

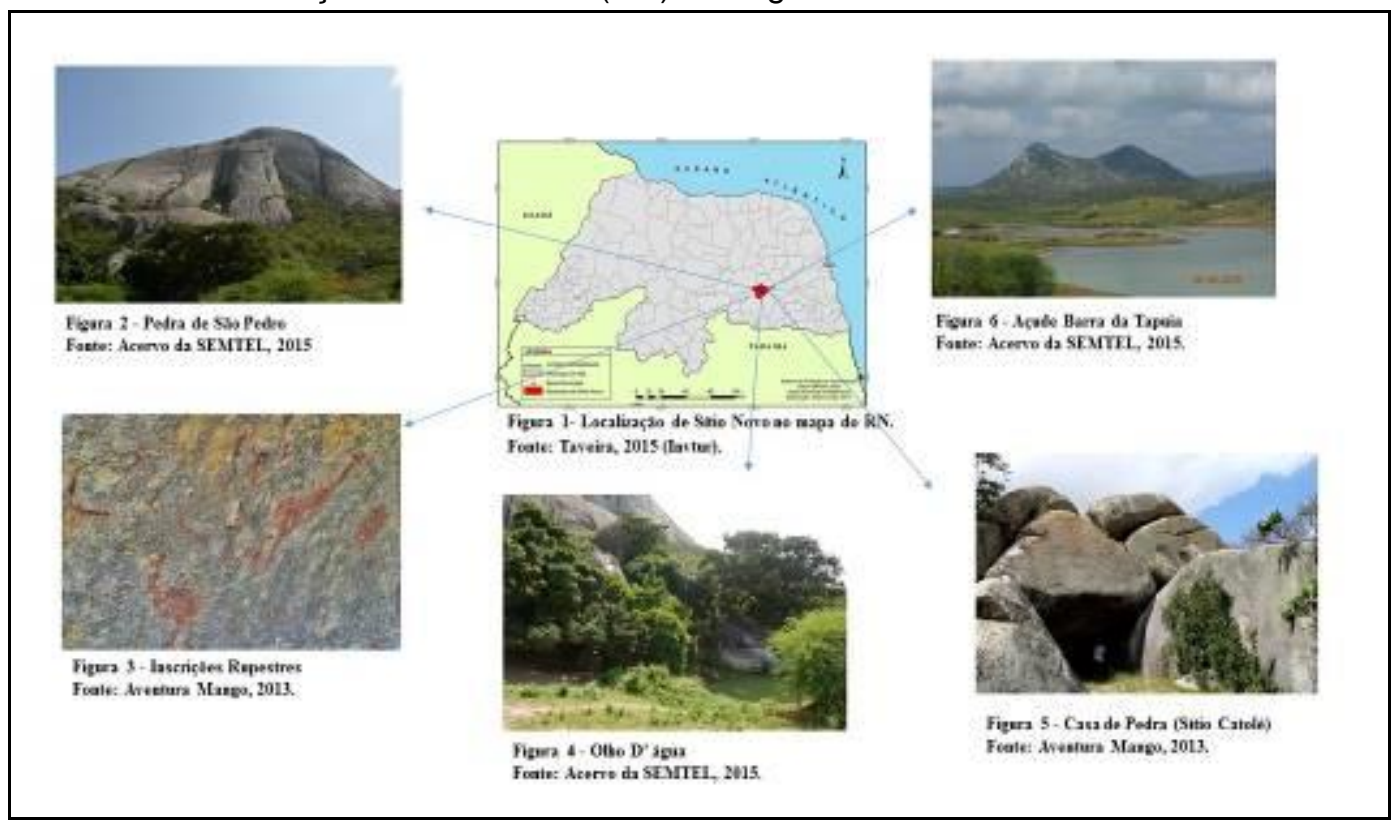

Fonte: Autoria própria (2015).

Em meio aos atrativos naturais apresentados, Taveira (2015) apresenta como atividades para serem desenvolvidas nesses lugares, o ecoturismo e os esportes de aventura. Elencando para atividades nos referidos ambientes, de uma maneira geral, a realização de Trilhas, Boulder, Rapel, Acampamento, Escaladas, Top Rop, Slackline, Spiroball, dentre outros, Passeio a Cavalo.

Salienta-se que nos dias atuais o território que vem sendo explorado, se referindo a visitações, é apenas a Pedra de São Pedro, os outros atrativos naturais citados encontram-se inexplorados até o momento. Entretanto, é pertinente verificar de que forma o uso desse território decorre, se há ou não a preocupação da comunidade local, bem como dos visitantes, quanto a preservação ambiental do lugar.

\section{Formas de uso do ambiente natural municipal de Sítio Novo}

Para levantamento das informações seguintes foi realizada visita de campo, desse modo, entendendo que dentre os atrativos naturais identificados, até o momento, apenas a Pedra de São Pedro no município de Sítio Novo vem sendo visitada com frequência, destaca-se neste tópico como é feito o uso do território que compreende essa área.

A Pedra de São Pedro, localizada no Sítio São Pedro, em 1910 era propriedade do senhor Sebastião Lourenço (COSTA, 1992). E nos dias atuais pertence ao Assentamento Pedra de São Pedro, cuja comunidade possui em média 30 habitantes. Em pesquisa realizada na Prefeitura Municipal de Sítio Novo, contatou-se que foi destinado um funcionário especialmente para cuidar desse território, sendo esse um morador do entorno. Apresenta-se como área 
natural de maior destaque no município, mas verificou-se que não há, até então, nenhuma orientação e/ou restrição de uso desse atrativo natural. O que pode ser observado são voluntários (não munícipes) que se reúnem esporadicamente para realizar a limpeza do local, dado que o responsável destinado pela prefeitura não faz o referido trabalho.

Quanto as inscrições rupestres existentes no território que compreende a Pedra de São Pedro, observou-se que não há até então nenhuma ação por parte da comunidade local, ou de outro órgão e/ou instituição, que priorize a conservação dessas, pelo contrário o que se identifica são atos de vandalismos no sentido de deteriorar essa paisagem. Já foram identificados inclusive o uso de corretivo escolar e carvão como itens de pichação (ato de escrever ou rabiscar em muros) (Figuras 7 e 8), o que prejudica e/ou danifica até mesmo as marcações feitas por grupos antepassados, que caracterizam a cultura local e servem como elemento atrativo para o desenvolvimento da atividade turística.

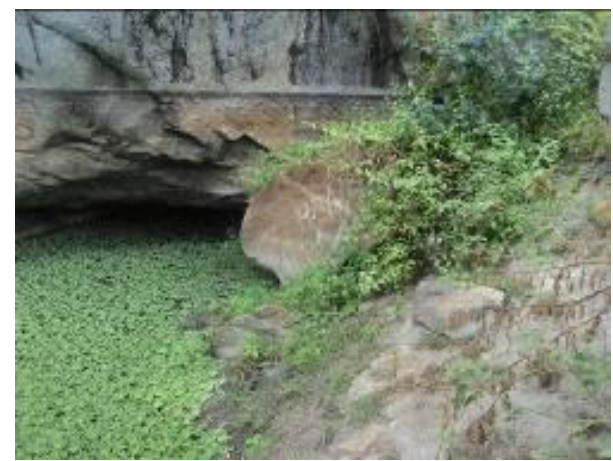

Figura 7: Pichação

Fonte: Acervo da autora (2015).

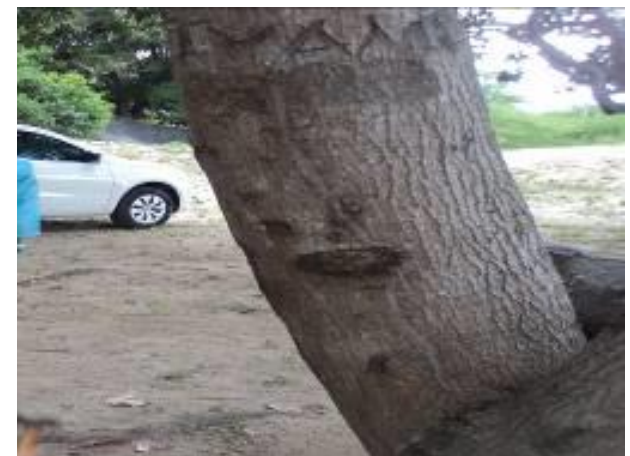

Figura 8: Ato de vandalismo

Fonte: Acervo da autora (2015).

Destaca-se ainda que não foi identificado no espaço que compreende a Pedra de São Pedro um responsável para orientar visitantes no que se refere as formas de uso e/ou, até mesmo, para orientar esses quanto a determinados tipos de comportamentos. Além do mais, não foi encontrado, também durante a visita ao local o responsável pelo zelo e limpeza do local, mesmo tendo constatado, em visita a prefeitura municipal que há um funcionário destinado para realização de tais tarefas (Figuras 9 e 10).

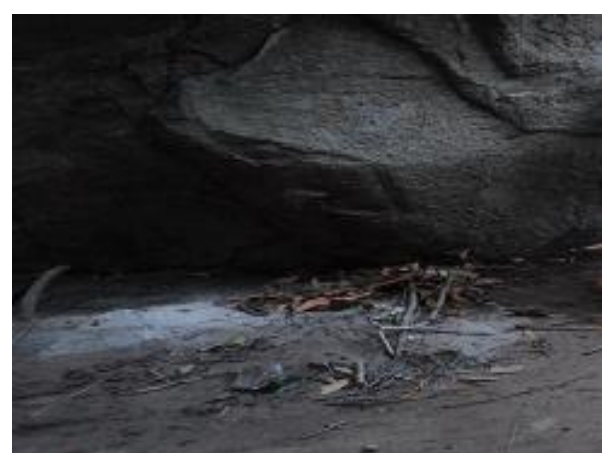

Figura 9: Queima de carvão Fonte: Acervo da autora (2015).

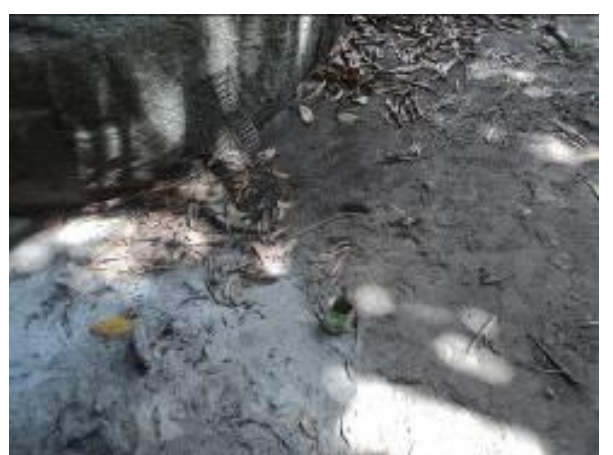

Figura 10: Atos de mal uso do ambiente Fonte: Acervo da autora (2015). 
No que se refere ao mirante do Cruzeiro São Francisco, a estrada que dá acesso ao atrativo não é pavimentada, e encontra-se obstruída com pedregulhos dificultando a passagem de carros, motos, ou outros tipos de transportes locais, como bicicleta e carroças. Vale esclarecer que a visitação nesse ambiente, até então, dar-se apenas pela comunidade local em procissão, especialmente no dia 04 de Outubro, dia do padroeiro da Serra da Tapuia, São Francisco de Assis.

As casas de pedras são elementos ainda não conhecidos, e, portanto, não foram encontrados registros de ações voltadas para a sensibilização da comunidade local quanto a existência desse tipo de recurso, nem estudos sobre a conjuntura da formação natural e histórica desses espaços.

\section{A Educação Ambiental no contexto escolar municipal}

O entendimento dos problemas ambientais causados, especialmente, pela ação humana precisa ser debatido e orientado com a finalidade de minimização desses, seja em esfera global ou local.

Dessa forma, conforme os PCNS (2000), promover o referido debate no âmbito escolar pode incluir a dimensão política e a perspectiva da busca de soluções para situações como a falta de saneamento básico adequado, por exemplo. E acrescenta que a problemática ambiental exige mudanças comportamentais, de discussão e construção de formas de pensar e agir na relação com a natureza. Nessa perspectiva, as perguntas elaboradas para fins desse estudo tiveram como base o livro dos PCNS que discute acerca do meio ambiente no contexto escolar.

Para tanto, investigou-se como os docentes das turmas de $5^{\circ}$ a $9^{\circ}$ ano da Escola Municipal Presidente Garrastazú Médici vem inserindo a problemática ambiental nas discussões em sala de aula. Salienta-se, portanto, que dos 9 professores que ministram aula nas referidas turmas, conseguiu-se um quantitativo de 7 respondentes. No entanto, apenas 6 devolveram os questionários da pesquisa. $O$ instrumento foi entregue durante um encontro pedagógico, momento em que os professores encontravam-se reunidos, tendo sido recolhidos em dias diferentes em função da disponibilidade de cada docente.

Quanto ao questionário, este buscou levantar, inicialmente, informações sobre o perfil dos respondentes no que se refere ao gênero (masculino e feminino), faixa etária, e disciplina ministrada, e com relação as perguntas específicas, destaca-se: 1- percepção sobre o que é educação ambiental; 2- se há realização de debates em sala de aula e quais os temas abordados; 3 - se as discussões acerca do meio ambiente estão inseridas nos currículos escolares como tema transversal, e de que forma isso acontece; 4se existem iniciativas de intervenção na realidade local em se tratando da temática ambiental; 5- se a escola vem contribuindo para uma formação da identidade dos alunos enquanto cidadãos conscientes de sua responsabilidade 
com o meio ambiente; e 6- se os docentes tem conhecimento de alguma política local voltada para o meio ambiente.

Quanto ao perfil dos respondentes, tem-se que 100\% desses foram mulheres, o que corresponde aos 6 professores participantes da pesquisa. A idade das docentes está compreendida da seguinte forma: $50 \%$ dos respondentes tem idade entre 20 e 30 anos; 33,3\% entre 30 e 40 anos; e $16,6 \%$ possui acima de 40 anos.

No que se refere as disciplinas ministradas, tem-se: (01) uma professora que ministra as disciplinas de língua portuguesa, inglês e espanhol; (01) uma professora de ciências; (01) uma professora de geografia; (01) uma professora de história; (01) uma professora que ministra apenas português; e (01) uma docente encontra-se no apoio pedagógico da escola.

Quanto aos questionamentos, a seguir destacam-se as seis perguntas que versam acerca da educação ambiental no âmbito escolar. Desse modo, a primeira questão refere-se ao entendimento dos docentes quanto ao que é educação ambiental (Quadro 2):

Quadro 2: Entendimento dos docentes acerca da Educação Ambiental.

\begin{tabular}{|l|l|}
\hline $\begin{array}{l}\text { Respondente } \\
\text { (1) }\end{array}$ & $\begin{array}{l}\text { "É o tipo de educação que objetiva formar cidadãos conscientes de seu papel } \\
\text { no ambiente, responsáveis por suas ações e que se utiliza de forma } \\
\text { equilibrada dos recursos naturais." }\end{array}$ \\
\hline $\begin{array}{l}\text { Respondente } \\
(2)\end{array}$ & "É necessária para a preservação do meio e do ambiente." \\
\hline $\begin{array}{l}\text { Respondente } \\
\text { (3) }\end{array}$ & $\begin{array}{l}\text { "Processo de educação responsável por formar indivíduos preocupados com } \\
\text { os problemas ambientais que busquem a conservação e preservação dos } \\
\text { recursos naturais para sustentabilidade." }\end{array}$ \\
\hline $\begin{array}{l}\text { Respondente } \\
\text { (4) }\end{array}$ & $\begin{array}{l}\text { "Processo educativo que conduz a um saber ambiental materializado nos no } \\
\text { valores de convívio social, está relacionada com a prática de decisões e a } \\
\text { ética que conduzem para a melhoria da qualidade de vida." }\end{array}$ \\
\hline $\begin{array}{l}\text { Respondente } \\
\text { (5) }\end{array}$ & $\begin{array}{l}\text { "Educação voltada para conscientização da importância que se deve ter da } \\
\text { relação natureza, ambiente e humano, apresentações de alternativas } \\
\text { existentes para a preservação do meio ambiente sendo de forma diária, } \\
\text { relacionando com a qualidade de vida." }\end{array}$ \\
\hline $\begin{array}{l}\text { Respondente } \\
\text { (6) }\end{array}$ & $\begin{array}{l}\text { "Conjunto de valores, comportamentos e atitudes éticas. Cuidado com o ser } \\
\text { humano e manutenção do meio de convivência." }\end{array}$ \\
\hline
\end{tabular}

Fonte: Autoria própria (2015).

Com relação as descrições acerca do entendimento do que vem a ser educação ambiental, nota-se que as respostas se complementam e os docentes apresentam percepções com elementos diferenciados, porém coerentes quanto a esse tipo de educação.

Assim, ressalta-se que os respondentes 1 e 3 apresentam uma percepção que está relacionada ao que Kindel (2012) apresenta, uma vez que educar ambientalmente, conforme o autor, estaria relacionado ao entendimento de conceitos e processos que tratam acerca do meio ambiente, de maneira a permitir que os indivíduos tenham um maior conhecimento quanto as relações 
complexas existentes entre os elementos naturais e socioculturais, e passem a respeitá-las em busca da sustentabilidade.

O respondente 4 destaca que EA está relacionada com a prática de decisões e a ética que conduzem a uma melhoria na qualidade de vida, estando assim em consonância com o que Nascimento e Araújo (2012) explicam, já que para os autores, a EA tem o papel de intermediar e reintegrar a relação homem/natureza, e isso irá perpassa por decisões, especialmente, no tocante ao processo educativo no ambiente escolar para fins de conscientização/sensibilização de crianças e jovens para modificações de condutas e comportamentos futuros.

Conforme o respondente 5 a EA volta-se para uma possível apresentação de alternativas com foco na preservação/conservação do meio ambiente a partir de uma educação que destaque a importância da relação natureza e ser humano, e em concordância Linder (2012) esclarece a EA como necessária para que as pessoas sejam esclarecidas e possam opinar e/ou decidir sobre formas de proteger o ambiente e a comunidade na qual vivem e convivem.

Em síntese, verificou-se que os professores, de uma maneira geral, possuem entendimento quanto ao significado da educação ambiental e compreendem sua importância para a formação cidadã do indivíduo. Entretanto, mesmo diante desse entendimento não possuem ações efetivas voltadas para essa perspectiva.

A segunda pergunta acerca da realização de debates em sala de aula com fins de encontrar soluções para situações que podem trazer danos a população, notou-se que $83,3 \%$ dos docentes são adeptos dessa prática, enquanto $16,6 \%$ não a realiza. Desse modo, dentre os temas abordados pelos docentes, destaca-se, ver (Figura 11):

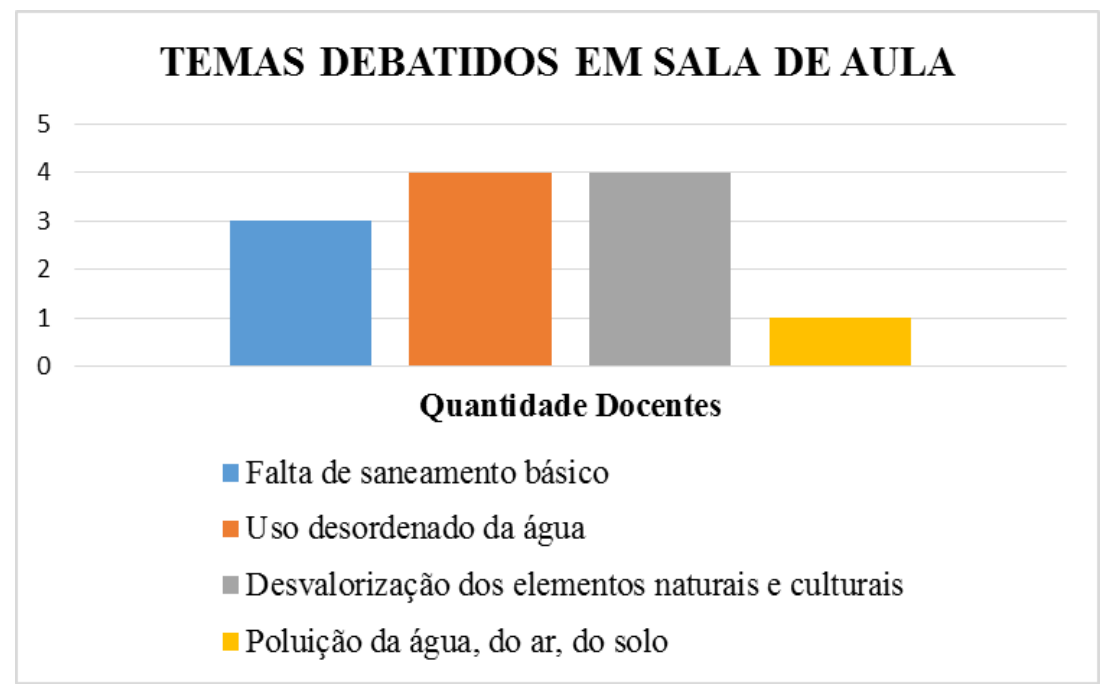

Figura 11: Temas debatidos em sala de aula. Fonte: Dados da pesquisa (2015). 
Percebe-se a partir do resultado, que os temas mais discutidos em sala de aula pelos docentes da escola são: desvalorização dos elementos naturais e culturais, e o uso desordenado da água, a saber, 4 (quatro) dos 6 (seis) professores discutem os referidos temas em sala de aula.

Frente a esse resultado, destaca-se que mesmo havendo tais discussões em sala de aula, ainda falta estabelecer um elo entre a comunidade escolar e a local no sentido de levar tais debates para além do referido espaço fisico, uma vez que observou-se deficiencia no processo de conscientização da comunidade local no que se refere ao cuidados, em especial, com os recursos naturais do lugar. Tal fato pode ser identificado a partir da observação da existência de pichações, degradações, em resumo, má conduta em ambientes que merecerem cuidados específicos.

A terceira questão indagava quanto a insersão da temática ambiental nas disciplinas curriculares de modo transversal, permeando toda prática educacional. Observou-se que $83,3 \%$ dos respondentes revelaram que isso acontece no âmbito escolar da Escola Municipal Presidente Medici, ao passo que $16,6 \%$ não visualiza tal feito. Assim, constatou-se que essa tranversalidade é estimulada por meio das seguintes práticas pedagógicas e/ou metodologias de ensino, ver (Figura 12):

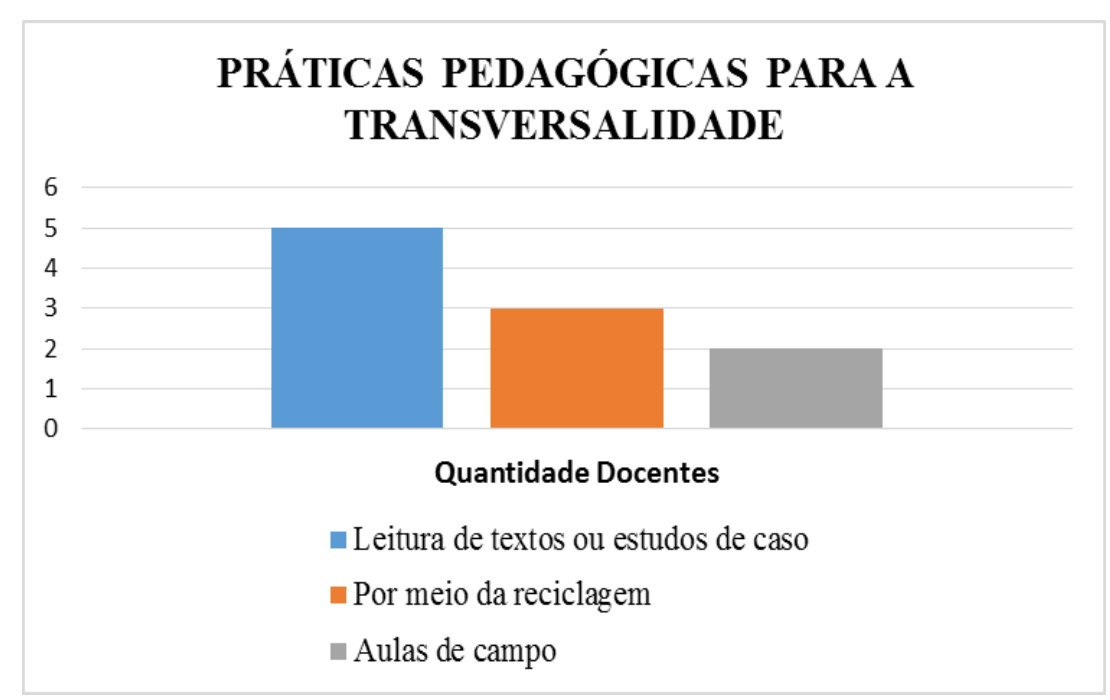

Figura 12: Práticas pedagógicas.

Fonte: Dados da pesquisa (2015). 
de aulas de campo, cuja intenção é aproximar o aluno da realidade local e buscar debater formas de solucionar determinados problemas.

Referindo-se a quarta pergunta essa foi quanto as iniciativas de intervenção na realidade local no tocante a temática ambiental. E com relação a este questionamento, contatou-se, conforme os docentes, que existem apenas projetos que precisam ser aplicados. Tendo sido mencionado no questionário que ações de mobilização foram feitas sim, mas até o momento apenas em prol da limpeza da escola.

O quinto questionamento tratou acerca da contribuição da escola para uma formação de cidadãos conscientes de sua responsabilidade ambiental. Observou-se que para $83,3 \%$ dos professores a escola vem contribuindo para esta formação, na medida em que $16,6 \%$ não esta de acordo com essa afirmação. Destaca-se, portanto, os trechos descritos no questionário que indicam como essa formação vem sendo feita (Quadro 3):

Quadro 3: Contribuição para formação dos alunos.

\begin{tabular}{|l|l|}
\hline $\begin{array}{l}\text { Respondente } \\
(1)\end{array}$ & $\begin{array}{l}\text { "Acredito que ainda não é de maneira sistemática, com prática planejada } \\
\text { que permei toda atividade escolar." }\end{array}$ \\
\hline $\begin{array}{l}\text { Respondente } \\
(2)\end{array}$ & "Conscientizando os alunos da importância do meio ambiente." \\
\hline $\begin{array}{l}\text { Respondente } \\
(3 \text { e 4) }\end{array}$ & "Respostas inespecíficas." \\
\hline $\begin{array}{l}\text { Respondente } \\
(5)\end{array}$ & "Acredito que a escola poderia e deveria promover mais e melhores ações \\
\hline $\begin{array}{l}\text { Respondente } \\
(6)\end{array}$ & "Através de um projeto que trata da reciclagem do lixo, tentanto \\
\hline
\end{tabular}

Fonte: Autoria própria (2015).

A partir das descrições, constatou-se que não há, até o momento, na escola em questão, uma maneira planejada e/ou ordenada com fins de dar uma formação mais específica aos alunos quanto as suas responsabilidades para com o meio ambiente, o que acontecem são ações pontuais que objetivam conscientiza-los da importância de manter um espaço coletivo de convívio diário limpo (ambiente escolar), ver respostas dadas pelos respondentes 1,2 , e 6 . Destaca-se que para o respondente 5 a escola deveria promover mais ações no tocante a prática da educação ambiental, o que demonstra necessidade de planejamento tanto de cada professor, referindo-se a sua disciplina específica, como revela uma oportunidade de se estar planejando ações em conjunto, considerando a possível contribuição de disciplinas diferentes para discussão de uma mesma temática.

Em resumo, verifica-se que não há ações efetivas e/ou planejadas e orientadas para discussão da temática ambiental no ambiente escolar que contribua de modo significativo para a formação de cidadãos conscientes de sua responsabilidade com o meio ambiente para além do âmbito escolar.

Em se tratando da sexta e última pergunta, referente ao conhecimento dos docentes quanto a existência de uma política local voltada para o meio 
ambiente, constatou-se que $100 \%$ dos respondentes desconhecem alguma política e/ou lei municipal que trate acerca dessa temática. E em função dessa pergunta buscou-se descobrir se o município dispõe de fato de uma política que nortei o uso dos espaços naturais ou que oriente o uso desses, mas não identificou-se nenhuma diretriz, até o presente momento.

\section{Conclusões}

O presente estudo teve como objetivo verificar como os docentes de uma escola da rede municipal de ensino de Sítio Novo (RN) abordam as questões ambientais em sala de aula. Para tanto, inicialmente, identificou-se os recursos naturais do referido município, e buscou-se caracterizar as formas de uso desses espaços, a fim de depois identificar como a educação ambiental é trabalhada no âmbito escolar.

Assim sendo, no que se refere aos recursos naturais, destaca-se o potencial natural do município de Sítio Novo, a partir da identificação de elementos como a Pedra de São Pedro (olho d'água, inscrições rupestres, cavernas e mirantes); o Tanque da Vaca (inscrições rupestres, cavernas, reservatório natural d'água); Serra da Pitombeira (cachoeira, cavernas, mirantes, reservatório d'água natural), e o Sítio Catolé (inscrições rupestres, cavernas, casa de pedra e mirantes). Tais recursos, que embelezam o lugar e diferenciam o município em termos de riquezas naturais, em sua maioria, ainda encontram-se inexplorados, esclarecendo que a Pedra de São Pedro apresenta-se, nos dias atuais, como um atrativo de grande interesse para aqueles que são adeptos do turismo, em especial do turismo de aventura.

Considerando, portanto, que o ambiente correspondente a Pedra de São Pedro vem sendo frequentemente visitado, notou-se a partir de visita de campo que há ausência de orientações para utilização do referido ambiente, bem como deficiência no que se refere a limpeza do lugar por parte do representante destinado pela Prefeitura Municipal para realização de tal atividade. Pensa-se perante a este fato, que há lacunas no gerenciamento de pessoas, além de faltar uma política local que destaque a importância e responsabilidade para com os recursos que o município dispõe.

Em função das visitas cada vez mais frequentes ao ambiente da Pedra de São Pedro, e a falta de gerenciamento dessa utilização no referido espaço, constatou-se uma depredação dos elementos naturais que ali encontram-se, como é o caso da depreciação das inscrições rupestres, das árvores, e do lixo "entulhado" no entorno do atrativo.

Diante dos recursos naturais existentes e da pertinência em trabalhar a temática ambiental no contexto escolar, dada a preocupação com o ambiente natural que irá ser apresentado as gerações futuras, observou-se que, em resumo, os docentes participantes do estudo ainda não dispõem de ações efetivas direcionadas e que levem em consideração as características do lugar para a formação de cidadãos conscientes de suas responsabilidades no 
tocante ao meio ambiente. São inseridos em sala de aula apenas práticas pedagógicas como: a leitura de textos que destacam a temática ambiental; a busca pela apresentação e relevância da reciclagem; e aulas de campo, realizadas de forma pontuais, uma vez que apenas dois dos seis professores citaram esta prática.

Percebeu-se um entendimento por parte dos respondentes quanto ao que é educação ambiental e sua importância no contexto escolar, entretanto, notou-se que esse fato ainda não foi debatido e incluindo em uma perspectiva transdisciplinar. Isso significa que os professores trabalham, muitas vezes, de forma isolada e pontual, perdendo a oportunidade de estabelecer uma maior colaboração entre os docentes de disciplinas diversas e assim atingir objetivos mais amplos, como é o caso de uma formação cidadã voltada para a sustentabilidade.

Desse modo, é preciso estimular os docentes a trabalharem de forma colaborativa no que se refere a discussão da temática ambiental no âmbito escolar, de maneira que as questões da vida cotidiana sejam inseridas nesse processo, e que as características locais sejam consideradas. Ressaltando, por fim, que a responsabilidade com os recursos naturais deve ser compartilhada, de outro modo, deve envolver além da comunidade escolar, o poder público, para fins de organização e normatização para o uso de certos ambientes naturais específicos.

Logo, como trabalhos futuros, sugere-se que sejam feitos estudos considerando a percepção do alunado referente ao entendimento desses quanto a importância dos recursos naturais locais existentes, destacando ainda o que esses pensam sobre as práticas pedagógicas realizadas pelos docentes para fins de discutir a temática ambiental no contexto escolar.

\section{Referências}

BRASIL. Parâmetros Curriculares Nacionais (PCN): Meio Ambiente. 2000. Disponível em: <http://portal.mec.gov.br/seb/arquivos/pdf/meioambiente.pdf>. Acesso em: 05 set. 2015.

BRASIL. Ministério do Meio Ambiente. Agenda 21. Disponível em: $<$ http://www.mma.gov.br/responsabilidade-socioambiental/agenda-21>. Acesso em: 02 set. 2015.

BRASIL. Lei no 9795 de 27 de abril de 1999. Institui a Política de Educação Ambiental. Disponível em: $<$ http://www.planalto.gov.br/ccivil 03/LEIS/L9795.htm>. Acesso em: 02 set. 2015.

COSTA, J. Sítio Novo e sua gente: Terra de São Sebastião. 1992.

FEMURN. Distâncias a Natal/RN. Disponível em: $<$ http://www.femurn.org.br/distancias-de-natal-rn>. Acesso em: 03 set. 2015. 
PORTAL EDUCAÇÃO. A Conferência de Estocolmo - 1972. 2012. Disponível em: <http://www.portaleducacao.com.br/biologia/artigos/20058/aconferencia-de-estocolmo-1972\#!2>. Acesso em: 02 set. 2015.

\section{DA CONFERÊNCIA. das Nações Unidas para o Meio Ambiente Humano, em Estocolmo, à Rio $\mathbf{- 9 2}$. Disponível em:} $<$ http://www.senado.gov.br/noticias/Jornal/emdiscussao/rio20/ario20/conferencia-das-nacoes-unidas-para-o-meio-ambiente-humanoestocolmo-rio-92-agenda-ambiental-paises-elaboracao-documentos-comissaomundial-sobre-meio-ambiente-e-desenvolvimento.aspx>. Acesso em: 02 set. 2015.

KINDEL, E.A.I. Educação Ambiental nos PCN. In: LISBOA, C.P.; LISBOA, E.A.l. (Org.). Educação Ambiental da teoria à prática. Editora Mediação: Ministério da Educação, 2012, p. 21-28.

O ESTADO. do Rio Grande do Norte. Disponível em: $<$ http://dc.itamaraty.gov.br/imagens-e-textos/revista1-mat12.pdf>. Acesso em: 01 nov. 2015.

LINDNER, E.L. Refletindo sobre o Meio Ambiente, In: LISBOA, C.P.; LISBOA, E.A.l. (Org.). Educação Ambiental da teoria à prática. Editora Mediação: Ministério da Educação, 2012, p. 13-19.

NASCIMENTO, A. G.; ARAÚJO, M. C. A Reciclagem de papel como ferramenta de educação ambiental na Escola Estadual Nestor Lima Natal/RN. In: SEABRA, G.; MENDONÇA, I. (Org.). Educação ambiental: responsabilidade para a conservação da sociobiodiversidade. João Pessoa: Editora Universitária da UFPB, V. 4, 2011. 28-31 p. Disponível em: $<$ http://www.cnea.com.br/wp-content/uploads/2013/03/ll-CNEA-

Educa\%C3\%A7\%C3\%A3o-Ambiental-responsabilidade-para-a-

conserva\%C3\%A7\%C3\%A3o-da-sociobiodiversidade- -Vol.4.pdf >. Acesso em: 02 set. 2015.

SANTOS, S.R.; SANTOS, P. Contribuições da Educação Ambiental para o Turismo Sustentável na APA do Maracanã, São Luís (Maranhão, Brasil). Turismo \& Sociedade. Curitiba, v. 4, n. 2, 265-285, outubro de 2011. Disponível em: <http://ojs.c3sl.ufpr.br/ojs/index.php/turismo/article/view/24763>. Acesso em: 02 set. 2015.

TAGORE, V. O que é Desenvolvimento Sustentável. 2009. Disponível em:<http://www.revistameioambiente.com.br/2009/03/12/o-que-edesenvolvimento-sustentavel/>. Acesso em: 02 set. 2015.

TAVEIRA, M.S. (coordenador). Inventário Turístico de Sítio Novo/RN. Currais Novos: UFRN, 2015.

PELICIONE, M.C.F. Fundamentos da Educação Ambiental. In: PHILIPPI JR, A.; ROMERO, M.A.; BRUNA, G.C. Curso de Gestão Ambiental. Editora: Manole, 2004, p. 459-483. 